\title{
The effect of nerve-sparing surgery on patient-reported continence post-radical prostatectomy
}

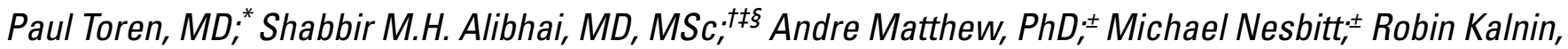 \\ BMus; Neil Fleshner, MD, FRCSC; ${ }^{*} \pm$ John Trachtenberg, MD, FRCSC ${ }^{*}$
}

See related article on page 471

\section{Abstract}

Introduction: Urinary continence significantly affects quality of life after radical prostatectomy (RP). The impact of nerve-sparing surgery on continence is unclear from the current literature.

Methods: We identified men with prostate cancer from the University Health Network Prostate Centre database who underwent RP. Preoperatively and at each postoperative visit, patients completed the Patient-Oriented Prostate Utility Scale (PORPUS), a validated psychometric and health utility instrument. Incontinence was defined by a single questionnaire item. Patients with radiotherapy or less than 10 months follow-up were excluded. Chi-squared tests and ANOVA were used to compare groups. Multivariable logistic regression was used to control for effects of nerve-sparing and other covariates.

Results: Of the 253 eligible patients from 2003 to 2007, 159 patients had bilateral nerve-sparing, 32 had unilateral nerve-sparing and 62 had non-nerve-sparing surgery. Of these patients, 27\%, 17\% and $34 \%$, respectively, were classified as incontinent at 1 year. These proportions were not significantly different between groups $(p=0.23)$. Multivariable logistic regression showed baseline urinary continence and urinary frequency to be significant predictors of patient-reported continence at 1 year postoperatively, with odds ratios of 1.7 (95\% confidence interval [Cl] 1.1-2.9) and 1.5 (95\% Cl 1.0-2.3), respectively.

There was a significant difference in the proportion of PORPUS sexual function scores between nerve-sparing groups after excluding those with baseline sexual dysfunction $(p=0.003)$. Similarly, health-related utility scores were different across groups $(p<0.001)$. Conclusion: Our results do not suggest a difference in 1-year patientreported continence based on the type of nerve-sparing RP. However, baseline continence and urinary frequency were significant predictors of continence at 1 year.

Can Urol Assoc J 2009;3(6):465-70

\section{Résumé}

Introduction : L'incontinence urinaire réduit grandement la qualité de vie après une prostatectomie radicale (PR). Or, les données publiées ne permettent pas d'établir l'impact sur la continence $d^{\prime}$ une intervention avec préservation des filets nerveux.

Méthodologie : Des hommes atteints de cancer de la prostate et ayant subi une PR ont été trouvés dans la base de données du
University Health Network Prostate Centre. Avant I'intervention et lors de chaque visite après celle-ci, les patients devaient utiliser le questionnaire PORPUS d'auto-évaluation, un instrument validé de psychométrie sur les troubles de la prostate et l'état de santé. Un seul point du questionnaire a trait à l'incontinence. Les patients ayant reçu une radiothérapie ou dont le suivi était inférieur à 10 mois étaient exclus. Les groupes ont été comparés à l'aide de tests du chi carré et d'analyses ANOVA. Une analyse de régression logistique multivariée a permis de vérifier les effets de la préservation des filets nerveux et d'autres covariables.

Résultats : Sur les 253 patients admissibles traités entre 2003 et 2007, 159 avaient subi une intervention bilatérale avec préservation des filets nerveux, 32, une intervention unilatérale avec préservation des filets nerveux et 62 , une intervention sans préservation des filets nerveux. De ces nombres, $27 \%$, $17 \%$ et $34 \%$ respectivement étaient considérés incontinents après un an. La proportion de patients incontinents $n$ 'était pas significativement différente entre les groupes $(p=0,23)$. L'analyse de régression logistique multivariée a fait ressortir que la continence urinaire et la fréquence mictionnelle au départ étaient des facteurs de prédiction importants de la continence évaluée par les patients un an après l'intervention, les rapports des risques étant respectivement de 1,7 (intervalle de confiance [IC] à $95 \%: 1,1$ à 2,9) et 1,5 (IC à $95 \%: 1,0$ à 2,3).

Une différence significative a été notée dans le taux de scores PORPUS de dysfonction sexuelle entre les groupes ayant subi une intervention avec préservation des filets nerveux, après exclusion des patients présentant une dysfonction sexuelle au départ ( $p=$ $0,003)$. De même, les scores concernant l'état de santé étaient différents d'un groupe à l'autre $(p<0,001)$.

Conclusion : Nos résultats ne portent pas à croire à l'existence $d^{\prime}$ une différence sur le plan de la continence un an après l'intervention en fonction du type de PR avec préservation des filets nerveux. Cependant, la continence et la fréquence mictionnelle au départ constituent d'importants facteurs de prédiction de la continence un an après I'intervention.

\section{Introduction}

The impact of quality of life on men post-radical prostatectomy $(\mathrm{RP})$ is significant and affects many domains. Urinary continence has been shown to be one of the strongest predictors of quality of life post-RP., 1,2 Population-based research has shown urinary function and, even more so, 
urinary bother has the strongest association with overall quality of life in prostate cancer patients, above even treatment modality or sexual function. ${ }^{2}$ In a well-constructed study, urinary continence also had the highest correlation between level of distress of patients' partners and patient's postoperative quality of life; this finding highlights the impact beyond the patient. ${ }^{1}$

Reported rates of urinary incontinence after nerve-sparing $\mathrm{RP}$ vary widely, ${ }^{2-4}$ based on the method of data collection (i.e., whether the data is patient-reported or physician-reported). ${ }^{5}$ Estimates from population-based studies suggest an overall $20 \%$ prevalence of post-RP patients who consider themselves to have any urinary incontinence. ${ }^{2}$ Recovery of continence post-RP is well-recognized to be a time-dependent process. Prospectively collected data suggest that continence improves up to at least 24 months after surgery. ${ }^{6}$

Previous studies have assessed factors that affected postoperative incontinence rates. ${ }^{3,6-11}$ In addition to nerve-sparing status, age and preoperative urinary function have been identified as independent factors in previous analyses. $3,6,9,12$

There are a number of retrospective prostatectomy series that shed some light on the issue of whether nerve-sparing surgery affects continence rates. ${ }^{3,6-8,10,11}$ More recent studies have specifically sought to answer the question of whether nerve-sparing prostatectomy affects continence outcomes..$^{9,12}$ Reviewing these studies, there is no consensus; some studies show a beneficial effect of nerve sparing on postoperative continence, ${ }^{3,6,9,11,12}$ while others demonstrate no effect. ${ }^{7,8,10,13}$ Sample size, the number of factors assessed, proportions of men undergoing nerve-sparing surgery and differences in analytic methods varied among positive and negative studies, making it difficult to draw any firm conclusions.

We reviewed the University Health Network Prostate Centre database to assess the impact of nerve-sparing surgery on patient-reported continence. With detailed clinical and pathological data, including comorbidities, we assessed whether nerve sparing had an impact on patientreported continence at 1 year post-RP.

\section{Methods}

We reviewed our database of patients who had an RP for clinically localized disease between May 2003 and January 2007. Institutional ethics board approval was obtained. All patients had biopsy-proven adenocarcinoma of the prostate. The Patient-Oriented Prostate Utility Scale (PORPUS), a validated 10-item prostate cancer specific health-related quality of life questionnaire, ${ }^{14,15}$ was prospectively selfadministered by patients preoperatively and at each followup clinic visit. We included only patients who had completed a preoperative questionnaire and at least 1 questionnaire 10 months or more after surgery, of which
Table 1. Urinary continence and frequency questions on the Patient-Oriented Prostate Utility Scale (PORPUS) instrument

\begin{tabular}{ll}
\hline Continence & Urinary frequency and urgency \\
$\begin{array}{l}\text { 1. Never, under any circumstances, } \\
\text { leak urine or lose bladder control }\end{array}$ & 1. No urinary frequency or urgency \\
\hline $\begin{array}{l}\text { 2. On rare occasions, leak urine or } \\
\text { lose bladder control, does not } \\
\text { interfere with any activities (e.g., } \\
\text { work, social, sexual, sleep) }\end{array}$ & $\begin{array}{l}\text { 2. A little urinary frequency, or } \\
\text { sleep or other activities (e.g., work, } \\
\text { social), no need to plan ahead }\end{array}$ \\
\hline $\begin{array}{l}\text { 3. Occasionally leak urine or lose } \\
\text { bladder control, interferes with a } \\
\text { few activities }\end{array}$ & $\begin{array}{l}\text { 3. Some urinary frequency or } \\
\text { urgency that interferes with sleep } \\
\text { or other activities, may need to } \\
\text { plan ahead }\end{array}$ \\
$\begin{array}{ll}\text { 4. A moderate amount of the time, } \\
\text { leak urine or lose bladder control, } \\
\text { interferes with many activities }\end{array}$ & $\begin{array}{l}\text { or urgency, need to be near a } \\
\text { bathroom most of the time }\end{array}$ \\
\hline $\begin{array}{l}\text { 5. Most of the time, leak urine or } \\
\text { have poor bladder control, } \\
\text { interferes with many activities }\end{array}$ & $\begin{array}{l}\text { 5. Extreme urinary frequency or } \\
\text { urgency, need to be near a } \\
\text { bathroom always }\end{array}$ \\
\hline $\begin{array}{l}\text { 6. Require a clamp, catheter, or } \\
\text { collecting bag because of leaking } \\
\text { urine or poor bladder control }\end{array}$ & \\
\hline
\end{tabular}

the response closest to 12 months was used for analysis. Patients who had underwent laparoscopic RP were excluded, as were those who had radiation therapy preoperatively or postoperatively within the study period. Nerve-sparing status was ascertained from the operative notes.

Incontinence was defined by a single item on the PORPUS questionnaire (Table 1). Patients responding, "occasionally leak urine or lose bladder control, interferes with a few activities" or worse were classified as incontinent. A second, less strict definition, using the next gradation on the PORPUS scale, where patients responding with "a moderate amount of the time, leak urine or lose bladder control" was also used to quantify incontinence that was more bothersome to patients, and more closely resembled a definition of requiring more than 1 urinary pad per day.

SPSS version 12.0 was used for all statistical analyses. The chi-square test was used to compare categorical data and ANOVA and Mann-Whitney $U$ tests were used for continuous data. Patients were compared between bilateral nerve-sparing, unilateral nerve-sparing and non-nervesparing groups. Univariate logistic regression analysis with incontinence as the dependent variable was performed with the following variables: age, prostate weight, invasion of seminal vesicles, bladder neck or capsule, pathologic node status, margin status, total pathological cancer volume, nervesparing status (present or absent), baseline PORPUS sexual function, urinary frequency and continence scores, preoperative transrectal ultrasound volume, baseline prostatespecific antigen (PSA), estimated blood loss, body mass index (BMI), pathologic Gleason grade and number of comorbidities $(0,1$, or $\geq 2)$. Variables with a $p<0.1$ were included in 
the multivariable analysis. With a sample size of about 250 and approximately $25 \%$ of patients being defined as incontinent, we aimed for a maximum of 5 to 6 variables to avoid overfitting our multivariable model.

\section{Results}

\section{Baseline characteristics}

A total of 267 patients were identified from our database with 1-year continence data. Two patients who had laparoscopic prostatectomy and 8 patients who had radiotherapy either pre-operatively or within the follow-up period were excluded. Of the 257 remaining patients in our sample, $159(63 \%)$ had bilateral nerve-sparing surgery, 32 (13\%) had unilateral nerve-sparing, and 62 (25\%) had non-nervesparing surgery. We were unable to determine nerve- sparing status of 4 patients' operation. In total, our sample size was 253 . Thirteen of the total number of patients $(n=$ 253) patients were classified as incontinent based on baseline continence scores (Fig. 1a).

Patients tended to be older in the non-nerve-sparing group $(p<0.001)$, had higher baseline PSA values $(p<0.029)$ and had a trend to larger prostates, measured by pathological weight $(p=0.051)$, and a trend to a higher BMI $(p=0.052)$. Not surprisingly, patients who received nonnerve-sparing surgery had worse preoperative sexual function scores $(p<0.001)$; however, baseline urinary continence scores were not significantly different between groups $(p=0.067)$. Pathological results were also as expected, with mean cancer volume being higher in non-nerve-sparing patients $(p<0.001)$.

Baseline health utility scores between groups (range 0.93$0.95)$ were not significantly different $(p=0.07)$. Baseline characteristics are summarized in Table 2.

Table 2. Baseline patient characteristics by nerve-sparing status

\begin{tabular}{|c|c|c|c|c|}
\hline & Bilateral & Unilateral & Non-nerve-sparing & $p$-value \\
\hline Number of patients & 159 & 32 & 62 & \\
\hline Mean age (SD) & $59.4(6.2)$ & $59.6(6.8)$ & $65.6(6.4)$ & $<0.001^{\dagger}$ \\
\hline $\mathrm{BMI}, \mathrm{kg} / \mathrm{m}^{2}$ (SD) & 26.7 (3.2) & $25.9(3.3)$ & $27.6(3.1)$ & $0.052^{\dagger}$ \\
\hline Median follow-up, days & 601 & 579 & 541 & $0.690^{\dagger}$ \\
\hline Mean prostate weight, g (SD) & $47.1(19)$ & $46.1(22)$ & $54.2(21)$ & $0.051^{\dagger}$ \\
\hline $\begin{array}{l}\text { Gleason scores } \\
\begin{array}{l}5-6 \\
7 \\
8-10\end{array}\end{array}$ & $\begin{array}{c}57 \\
97 \\
3\end{array}$ & $\begin{array}{c}3 \\
27 \\
2\end{array}$ & $\begin{array}{c}9 \\
44 \\
8\end{array}$ & $<0.001^{\dagger \dagger}$ \\
\hline Mean cancer volume, mL (SD) & $8.1(9)$ & $8.3(7)$ & $15.3(13)$ & $<0.001^{\dagger}$ \\
\hline Capsular invasion & 32 & 8 & 32 & $<0.001^{\dagger \dagger}$ \\
\hline Seminal vesicle invasion & 12 & 2 & 11 & $0.266^{t \dagger}$ \\
\hline Bladder neck invasion & 0 & 1 & 3 & $0.077^{\dagger \dagger}$ \\
\hline Node positive disease & 0 & 1 & 2 & $<0.001^{\dagger \dagger}$ \\
\hline Extra-prostatic extension & 32 & 11 & 31 & $<0.001^{\dagger \dagger}$ \\
\hline Positive surgical margins & 15 & 6 & 18 & $<0.001^{\dagger \dagger}$ \\
\hline Mean PSA level, ng/mL (SD) & $6.55(6.4)$ & $6.24(2.8)$ & $8.97(6.5)$ & $0.029^{\dagger}$ \\
\hline Mean blood loss, mL (SD) & $587(408)$ & 616 (329) & $723(552)$ & $0.131^{\dagger}$ \\
\hline Mean baseline sexual function score (SD) & $1.7(1.0)$ & $1.8(1.0)$ & $2.4(1.4)$ & $0.001^{\dagger}$ \\
\hline Mean baseline urinary frequency score (SD) & $1.9(0.8)$ & $1.8(0.8)$ & $2.1(0.8)$ & $0.150^{\dagger}$ \\
\hline Mean baseline continence score (SD) & $1.3(0.6)$ & $1.4(0.6)$ & $1.5(0.8)$ & $0.123^{\dagger}$ \\
\hline $\begin{array}{l}\text { Comorbidities } \\
\quad 0 \\
1 \\
\geq 2\end{array}$ & $\begin{array}{c}104 \\
42 \\
13\end{array}$ & $\begin{array}{c}22 \\
8 \\
2\end{array}$ & $\begin{array}{c}36 \\
17 \\
8\end{array}$ & 0.741 \\
\hline
\end{tabular}




\section{One-year continence and health utility values}

At 1 year, $27 \%$ of bilateral nerve-sparing patients, $17 \%$ of unilateral nerve-sparing and $34 \%$ of non-nerve-sparing patients were classified as incontinent. Using the less strict definition, $9.5 \%, 6.7 \%$ and $10.3 \%$ of patients, respectively, were classified as incontinent at 1 year (Fig. 1b). The proportion of patients classified as incontinent was not significantly different between those who had nerve-sparing surgery and those who did not $(p=0.232)$. A separate analysis, excluding those with baseline sexual dysfunction, showed that the proportion of those with good sexual function was significantly different $(p=0.003)$ between groups.

Comparing health utility values at 1 year, there was a significant difference between nerve-sparing patients (0.89) and non-nerve-sparing surgery patients $(0.84)(p<0.001)$. These both also had significantly decreased from baseline values $(p<0.001)$.

\section{Factors predicting urinary continence}

Six variables were predictive of urinary incontinence on univariate analysis using a cut-off of $p<0.1$ : age, baseline sexual function, baseline continence, baseline urinary frequency scores, nerve-sparing status and pathologic cancer volume. We decided to exclude cancer volume from our multivariable analysis because our patients generally had small volume disease, and this variable was nonsignificant when analyzed dichotomously. Additionally, it had the most missing data $(n=49)$. After exclusions for missing data, 243 patients were included in the multivariable model. Multivariable analysis (Table 3) showed that baseline con- tinence and urinary frequency were the only significant predictors of patient-reported continence at 1 year post$\mathrm{RP}$, with odds ratios of 1.7 (95\% confidence interval [CI] 1.1-2.9) and 1.5 (95\% Cl 1.0-2.3), respectively.

\section{Discussion}

Clinically, it would be useful to identify patients who are at risk of urinary incontinence after surgery and thus be able to more intelligently select therapy to minimize complications and minimize any adverse impact on quality of life. Similarly, identification of factors affecting quality of life allows better preoperative counselling of patients. Specifically, knowledge of the effect of nerve-sparing surgery on urinary continence, as it does with sexual function, may affect the decision on whether to perform nervesparing surgery.

While several previous studies have found nervesparing status to be a predictor of postoperative return of continence on multivariate anaylsis, $3,9,11$ the present study did not verify this finding. We controlled for many cofactors, including number of comorbidities, which were not controlled for in previous studies. $6,8,9,11,12$ It is plausible that nerve-sparing surgery has acted as a surrogate for such factors unmeasured in previous series. Healthier patients are more likely to have nerve-sparing surgery, as they are also more likely to desire nerve-sparing surgery.

Previous reports in high-volume centres have mirrored our results, ${ }^{10,16}$ as well as a smaller representative study in both community and academic centres. ${ }^{13}$ Although our rate of nerve-sparing surgery was lower than in other series, our data did show a strong correlation between factors affect-

\begin{tabular}{|c|c|c|c|c|}
\hline Study & $\mathrm{N}$ & Assessment scale & Nerve-sparing, \% & Non-nerve-sparing, $\%$ \\
\hline Present study & 253 & $\begin{array}{l}\text { 1. Never leak } \\
\text { 2. On rare occasion, leak urine } \\
\text { 3. Occasionally, leak urine } \\
\text { 4. A moderate amount of the time, leak urine } \\
\text { 5. Most of the time, leak } \\
\text { 6. Require a clamp, catheter }\end{array}$ & $\begin{array}{c}13 \\
60 \\
17 \\
7 \\
3 \\
0.6\end{array}$ & $\begin{array}{c}15 \\
47 \\
31 \\
3 \\
5 \\
0\end{array}$ \\
\hline Talcott et al. $(1997)^{13}$ & 66 & $\begin{array}{l}\text { 1. Leaks or dribbles "a lot" } \\
\text { 2. Absorbent pad use }\end{array}$ & $\begin{array}{l}14 \\
50\end{array}$ & $\begin{array}{l}11 \\
14\end{array}$ \\
\hline Wei et al. $(2000)^{6}$ & 482 & $\begin{array}{l}\text { 1. Do you have a problem with leaking or } \\
\text { dripping urine? } \\
\text { 2. On average, how often do you leak or drip } \\
\text { urine? } \\
\text { 3. To control your leakage, you most often } \\
\text { wear how many pads per day? }\end{array}$ & $\begin{array}{l}32 \\
16 \\
5\end{array}$ & $\begin{array}{l}47 \\
25 \\
11\end{array}$ \\
\hline Lepor et al. $(2004)^{8}$ & 500 & $\begin{array}{l}\text { 1. Total control } \\
\text { 2. Occasional dribbling } \\
\text { 3. Frequent dribbling } \\
\text { 4. No control }\end{array}$ & $\begin{array}{l}49 \\
46 \\
3.5 \\
1.3\end{array}$ & $\begin{array}{l}\text { N/A } \\
\text { N/A } \\
\text { N/A } \\
\text { N/A }\end{array}$ \\
\hline
\end{tabular}


ing the decision to not perform nerve-sparing RP. Cancer volume, PSA and other pathologic features were worse in the non-nerve-sparing group, as well as baseline sexual and urinary functional scores and comorbidities. Our patients were also generally older patients, with more severe disease than that reported in other series, ${ }^{7,10}$ making our results more generalizable.

Baseline urinary continence and urinary frequency were the 2 factors found to be significant in our multivariable analysis. It has been previously noted that preoperative continence scores are significantly associated with postoperative return of continence, and this relationship is not surprising. The wording of our continence question, which also included the words "or lose bladder control," may have overlapped with patients' response to the amount of urinary frequency and urgency. Questions from the PORPUS instrument for both urinary continence and frequency are shown in Table 1. Part of the explanation may represent patients' sensitivity to the amount of urine leakage. Clinically, it seems that some patients complain of leakage when the objective amount they leak is minimal, while others with more leakage may report minimal symptoms. We were unable to explore this issue in detail as we did not objectively measure urine leakage in our patients.

While there was no significant difference between the proportion of patients defined as incontinent between groups, we did see a significant difference between patients who were defined as impotent between nerve-sparing and those without nerve-sparing surgery. This finding further validates the efficacy of our nerve-sparing surgery and our ability to distinguish nerve-sparing from non-nerve-sparing surgery

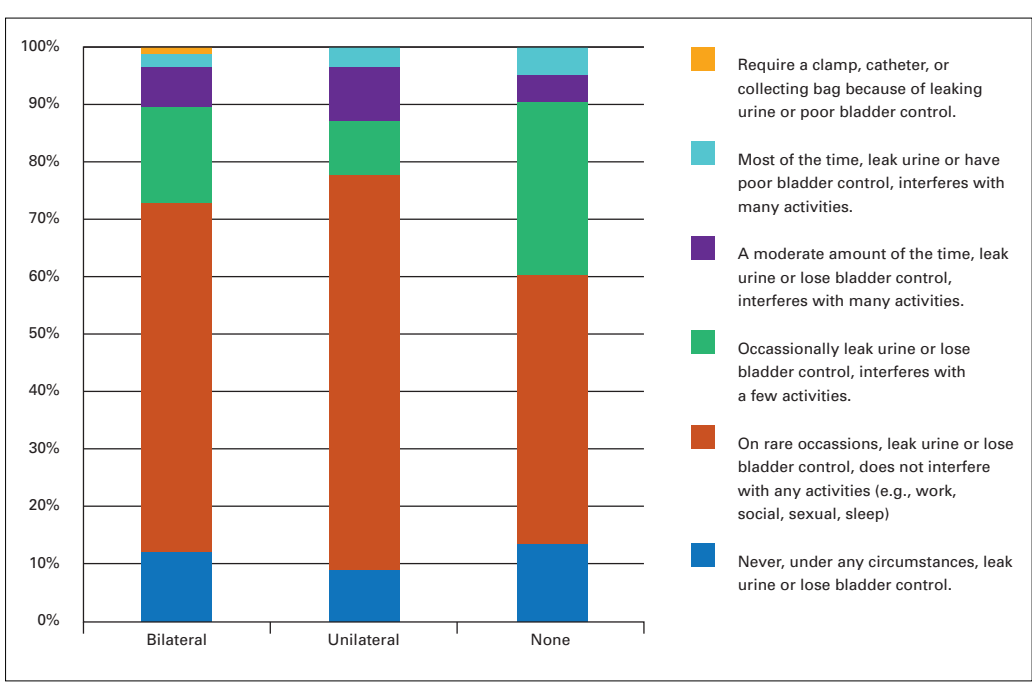

Fig. 1b. One-year Patient-Oriented Prostate Utility Scale (PORPUS) continence scores by nerve-sparing status. patients.

Although our definition for incontinence was different than that in previous studies, our 1-year incontinence rates are comparable to other patient-reported results reported in the literature. ${ }^{6,17}$ Table 3 suggests that the rate of incontinence is related in large part to the question used; notably, our population shows a more continuous distribution of continence scores compared with the other listed series. Although there could exist some difference between centres or surgeons, it seems apparent that the continence rate depends upon the question asked to the patient. Previous comparisons of physician-reported versus patient-reported continence have shown the difference to be as large as $21 \%$ versus $97 \%$, respectively. ${ }^{18}$ The main instrument we used in our study, the PORPUS, has been validated against other measures, such as the University of CaliforniaLos Angeles Prostate Cancer Index. ${ }^{15}$

There are limitations to our study that should be acknowledged. Sample size is one such limitation, as reflected in some overlapping confidence intervals in the univariate and multivariable analysis. We may not be able to exclude a small effect of nerve-sparing surgery on continence. Nonetheless, using our validated questionnaire, our study has a larger number of patients who experienced the outcome evaluated (incontinence) than several larger studies, 7,8,10 making our multivariable analyses more robust. While using patient-reported symptoms is arguably the most relevant when defining incontinence, our data do not have more objective measures, which could be helpful when comparing to some series. More research in this area would be helpful. Our study is also limited by including only English-speaking patients at a single centre. 


\section{Conclusion}

Our results do not suggest a difference in 1-year patientreported continence based on type of nerve-sparing RP. However, baseline continence as well as urinary frequency were significant predictors of 1-year continence.

From the *Department of Surgery, University of Toronto; ${ }^{\dagger}$ Department of Medicine, University Health Network; `Department of Medicine, University of Toronto; §Department of Health Policy, Management and Evaluation, University of Toronto; ${ }^{ \pm}$The Prostate Centre, University Health Network, Toronto, ON

Competing interests: Dr. Fleshner's disclosures are: Astra-Zeneca, consultant/advisor; GlaxoSmithKline, consultant/advisor; Merck Frosst, consultant/advisor; sanofi-aventis, consultant/advisor; Novartis, consultant/advisor; Pfizer, consultant/advisor. The other authors have no competing interests to declare.

This paper has been peer-reviewed.

\section{References}

1. Sanda MG, Dunn RL, Michalski J, et al. Quality of life and satisfaction with outcome among prostatecancer survivors. N Engl J Med 2008;358:1250-61.

2. Penson DF, Feng Z, Kuniyuki A, et al. General quality of life 2 years following treatment for prostate cancer: What influences outcomes? results from the prostate cancer outcomes study. J Clin Oncol 2003;21:1147-54.

3. Eastham JA, Kattan MW, Rogers E, et al. Risk factors for urinary incontinence after radical prostatectomy. J Urol 1996;156:1707-13.

4. Litwin MS, Pasta DJ, Y $\mathrm{Y} J$, et al. Urinary function and bother after radical prostatectomy or radiation for prostate cancer: A longitudinal, multivariate quality of life analysis from the cancer of the prostate strategic urologic research endeavor. J Urol 2000;164:1973-7.
5. Krupski TL, Saigal CS, Litwin MS. Variation in continence and potency by definition. J Urol 2003;170: 1291-4.

6. Wei JT, Dunn RL, Marcovich R, et al. Prospective assessment of patient reported urinary continence after radical prostatectomy. J Urol 2000;164:744-8.

7. Walsh PC, Marschke $P$, Ricker $D$, et al. Patient-reported urinary continence and sexual function after anatomic radical prostatectomy. Urology 2000;55:58-61.

8. Lepor H, Kaci L. The impact of open radical retropubic prostatectomy on continence and lower urinary tract symptoms: A prospective assessment using validated self-administered outcome instruments. J Urol 2004;171:1216-9.

9. Burkhard FC, Kessler TM, Fleischmann A, et al. Nerve sparing open radical retropubic prostatectomydoes it have an impact on urinary continence? J Urol 2006;176:189-95.

10. Kundu SD, Roehl KA, Eggener SE, et al. Potency, continence and complications in 3,477 consecutive radical retropubic prostatectomies. J Urol 2004;172:2227-31.

11. Sacco E, Prayer-Galetti T, Pinto F, et al. Urinary incontinence after radical prostatectomy: Incidence by definition, risk factors and temporal trend in a large series with a long-term follow-up. BJU Int 2006;97: $1234-41$.

12. Nandipati KC, Raina R, Agarwal A, et al. Nerve-sparing surgery significantly affects long-term continence after radical prostatectomy. Urology 2007;70:1127-30.

13. Talcott JA, Rieker P, Propert KJ, et al. Patientreported impotence and incontinence after nerve-sparing radical prostatectomy. J Natl Cancer Inst 1997;89:1117-23.

14. Krahn M, Ritvo P, Irvine J, et al. Construction of the patient-oriented prostate utility scale (PORPUS): A multiattribute health state classification system for prostate cancer. I Clin Epidemiol 2000;53:920-30.

15. Ritvo P, Irvine J, Naglie G, et al. Reliability and validity of the PORPUS, a combined psychometric and utility-based quality-of-life instrument for prostate cancer. I Clin Epidemiol 2005;58:466-74.

16. Steiner MS, Morton RA, Walsh PC. Impact of anatomical radical prostatectomy on urinary continence. J Urol 1991;145:512-4; discussion 514-5.

17. Augustin H, Pummer K, Daghofer $F$, et al. Patient self-reporting questionnaire on urological morbidity and bother after radical retropubic prostatectomy. Eur Urol 2002;42:112-7.

18. Litwin MS, Lubeck DP, Henning JM, et al. Differences in urologist and patient assessments of health related quality of life in men with prostate cancer: Results of the CaPSURE database. J Urol 1998;159: 1988-92.

Correspondence: Dr. John Trachtenberg, Princess Margaret Hospital, 4th Floor, Rm 4-926, 620 University Avenue, Toronto, ON M5G 2C1; fax: 416-598-9997; john.trachtenberg@uhn.on.ca 